\title{
A Pragmatic Approach to The Parasitic Gap Construction in Chinese
}

\section{Dawei Jin ${ }^{1}$}

LSA Annual Meeting, Minneapolis, January 2-5, 2014

1. Introduction. Chinese allows extraction from adjuncts in parasitic environment like many languages (Engdahl, 1983; Culicover, 2001), as the following contrast shows.

$$
\text { a. }{ }^{*} \text { Laoban [mianshi wan } \mathbf{t} \text { yihou] qu chi fan le] de yingpinzhe }
$$
boss interview PFV after go eat meal PFV REL applicant

'The applicant $\mathrm{i}_{i}$, who the boss went to meal after interviewing _i'

b. [Laoban [mianshi wan $\mathbf{t}_{1}$ yihou] jueding luyong $\mathbf{t}_{2}$ ] de yingpinzhe boss interview PFV after decide recruit REL applicant

'The applicant ${ }_{i}$, who the boss decided to recruit _i after interviewing _i'

In (1a) extraction across an adjunct is not possible, but no unacceptability is witnessed when an additional gap occurs in the matrix clause, as in (1b). I argue that data from Chinese provide evidence that parasitic gap construction should be accounted for by pragmatic reasons, instead of structural ones. This argument follows naturally from the claim that adjunct island effects in Chinese are not conditioned by syntactic locality constraints.

2.Previous Theories. Previous theories of Chinese parasitic gap construction (e.g., Lin, 2005; Ting and Huang, 2008) assume that the explanation for the construction's circumvention ability is syntactic. In a nutshell, these theories rely on the following two assumptions.

First, adjunction in Chinese is believed to create a strong island domain, as is generally assumed for other languages. This can be schematized as follows (cf.1a):

\section{(2) * [adjunct $\left.\mathrm{t}_{\mathrm{i}}\right]$ de yingpinzhe $\mathrm{i}_{\mathrm{i}}$}

Here an operator-variable chain cannot be formed if the chain has to span across an adjunct domain, because a locality constraint bans movement from across the adjunct, and this movement is necessary to form the operator-variable chain.

Second, parasitic gap construction is argued to be able to circumvent the locality constraint thanks to a mechanism of chain composition (Contreras, 1981; Chomsky, 1982), shown in (3) (which represents the mechanism for 1b).

$$
\left[\ldots\left[\mathrm{O}_{i}\left[\text { adjunct } \mathrm{t}_{\mathrm{i}}\right]\right] \ldots \mathrm{t}^{\prime}{ }_{\mathrm{i}} \ldots\right] \text { de yingpinzhe }{ }_{i}
$$

Here a null operator $\mathrm{O}_{\mathrm{i}}$ is adjoined to the [Spec,CP] position of the adjunct and forms a chain $\Sigma_{1}$ with the gap in the adjunct, i.e., $\Sigma_{1}=\left(\mathrm{O}_{\mathrm{i}}, \mathrm{t}_{\mathrm{i}}\right)$. On the other hand, the head noun of the relative clause forms another chain $\Sigma_{2}$ with the gap in the matrix clause within the relative, i.e. $\Sigma_{2}=\left(\right.$ yingpinzhe $\left._{\mathrm{i}}, \mathrm{t}_{\mathrm{i}}\right)$; The two chains, $\Sigma_{1}$ and $\Sigma_{2}$, form a composition relationship $\left(\Sigma_{1}, \Sigma_{2}\right)$, which makes interpretation possible.

3.Circumvention Effects. In this paper, I will not go into details about how well-grounded the above-mentioned chain composition mechanism is, as a fair share of the previous literature has

\footnotetext{
${ }^{1}$ I would like to thank Rui Chaves, Yoshi Asao, Natsuko Nakagawa and Jun Chen for useful comments. Author: Dawei Jin, the State University of New York at Buffalo (daweijin@buffalo.edu).
} 
already been devoted to this issue. ${ }^{2}$ Instead, I will present a series of empirical data in Chinese that pose a general challenge to treating Chinese parasitic gap construction syntactically. In essence, I argue that, even in nonparasitic contexts (when the adjunct clause contains a lone gap), island circumvention is possible in Chinese. ${ }^{3}$

First, (1a) becomes felicitous under a context where the head noun is interpreted as being identified from a set of contrastive alternatives.

[Laoban [mianshi wan t yihou] qu chi fan le] de yingpinzhe

Boss interview PFV after go eat meal PFV REL applicant

'the (very) applicant ${ }_{i}$ which, (out of all the applicants the boss interviewed), the boss

(happened to) go out for meal after interviewing _i'

Second, island effects disappear when the adjunct and the matrix clause stand in one of the coherence relations as identified by Hobbs (1979) (see also Kehler, 2012).

[Laoban [mianshi wan t yihou] jueding buzai kaolü qita

Cause-Effect

boss interview PFV after decide not consider other

renxuan] de yingpinzhe

candidate REL applicant

'the applicant ${ }_{i}$, who the boss interviewed _ $\mathrm{i}$ and then decided not to consider other candidates'

(6)

[Chubanshang [duguo t yihou] like jueding qian

Result

Publisher read after immediately decide sign

chubanhetong] de nei ben xiaoshuo

contract REL DEM CLF novel

'The novel $\mathrm{i}_{\mathrm{i}}$, which the publisher immediately decided to sign a contract after reading_i'

(7) [Chubanshang [jueding chuban t yihou] zuozhe fan'er

Publisher decide publish after author nevertheless

bu xiang hezuo] de nei ben xiaoshuo

be.reluctant collaborate REL DEM CLF novel

'The noveli, which the author didn't want to collaborate after the publisher decided to publish $_{i}$,

Therefore, we see that in Chinese, adjunct island effects don't depend on whether the matrix clause contains a gapped argument slot or not, but are sensitive to contextual factors. This suggests itself for a pragmatic explanation.

4.My Proposal. Based on these counterexamples, I put forward an alternative reasoning to handle the adjunct islands and parasitic gap phenomena in Chinese. I propose that, in general, the grammar should freely allow extraction to occur from across an adjunct clause, and island effects arise because structurally-independent pragmatic conditions are violated.

One such condition is the inherent function for any restrictive relative clauses to narrow down the referents of its head noun, such that out of all the possible discourse referents that a

\footnotetext{
${ }^{2}$ See Levine et al (2001) for a survey for the previous literature on chain composition.

${ }^{3}$ I thank Jun Chen, Lihua Xu, an anonymous reviewer of the LSA annual meeting and a group of native-speaking undergraduate students in the State University of New York at Buffalo for their judgment. For the examples below judgments are converging.
} 
head noun may refer to, only those that bear the relative-denoted property are being anchored. This condition is independently needed for all the adjunct relativization examples here, because they all involve a restrictive reading.

For this condition to be successfully obeyed, we need to discuss how its implementation process looks like. Discourse referents can be seen as being stored like file cards (Reinhart, 1981; Heim, 1982). When an assertion is made about a discourse referent, the information expressed by the assertion is stored in the process of context update. Therefore, identification/anchoring of a discourse referent is successful iff the information expressed by the relative clause has already been stored in the mental representation of that discourse referent. In this sense, the utterance of a restrictive relative clause is seen as a retrieval process that finds a file card by locating a previously updated property and anchors the referent of the entity on that file card, shown in Figure 1.

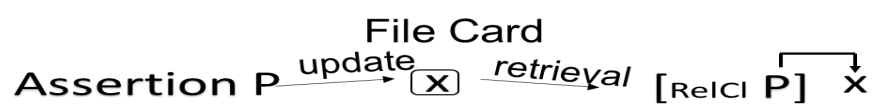

Figure 1

This process relates to relativization from adjuncts. In (1a), the relative clause contains two parts: an adjunct clause and a matrix clause. The adjunct clause describes an event $\mathrm{e}_{0}$ about an applicant x; The matrix clause describes an event of the boss, which occurs after $\mathrm{e}_{0}$. If this event is only temporally contiguous with $\mathrm{e}_{0}$ and is not construed as correlated during the context update, it is not normally stored in the mental representation (file card) of the applicant x. This means that the whole relative clause is not normally construed as identifying an applicant. As a result, the function of a restrictive relative clause is violated. This process is illustrated in Figure 2.

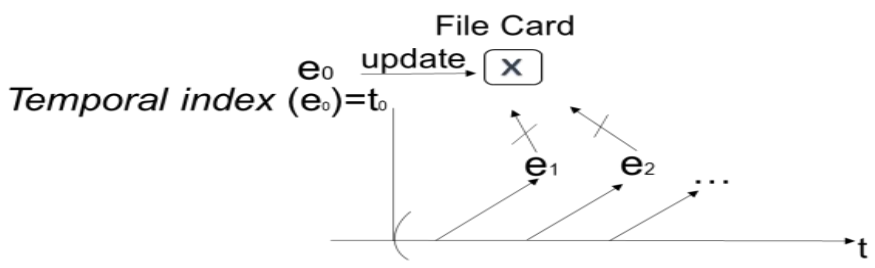

Figure 2

In the contrastive alternative scenario of (4), the adjunct describes an event type shared by all interviewees. It is the matrix event that distinguishes the interviewing events from each other. Under such a scenario, information about the matrix events is stored for different interviewees. This is demonstrated in the schema in Figure 3.

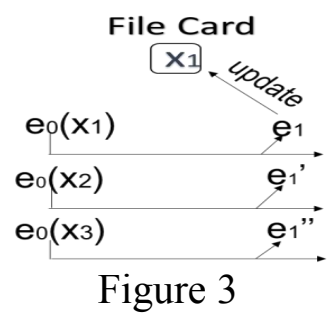

Here each interviewee (e.g. $\mathrm{x}_{1}, \mathrm{x}_{2}, \mathrm{x}_{3}$ ) participates in an interviewing event of the type $\mathrm{e}_{0}$. The temporally subsequent events they each participate in after $\mathrm{e}_{0}$, here represented as $\mathrm{e}_{1}, \mathrm{e}_{1}$ ', $\mathrm{e}_{1}$ ' and so on, are also stored and updated to their respective file cards. Consequently, the function of a restrictive relative clause is satisfied by uttering (4). 
Similarly, if an event $\mathrm{e}_{1}$ is temporally contiguous with $\mathrm{e}_{0}$ and also forms a coherence relation with $\mathrm{e}_{0}$, it is often updated to the file card of $\mathrm{e}_{0}$ 's discourse referent. For example, in (5) the matrix event $\mathrm{e}_{1}$ is the effect caused by the adjunct event $\mathrm{e}_{0}$, and is normally stored in the information about the causer.

5.Parasitic Gaps. If the matrix clause contains a gap, then that clause always describes an event participated by the gapped constituent, i.e., an event participated by the head noun. Therefore, the whole relative clause necessarily describes a property of the head noun. Crucially, parasitic gap constructions like (1b) function in this way, hence the restrictive function is always satisfied. Thereby, parasitic gap construction needs no specialized explanation, but falls within the more general case of the relative clause construction whose matrix clause is gapped.

6.Implications. The above data from Chinese suggest that parasitic gap constructions, as well as adjunct islands in general, are discourse-pragmatically conditioned. This differs from other nonstructural theories of adjunct islands, which derive the island phenomena from semantic constraints (see Truswell, 2010). Furthermore, this theory echoes the intuition that parasitic gaps and across-the-board extraction from conjuncts are related (Huybregts and van Riemsdijk, 1987; Williams, 1990). The latter has been explained in terms of coherence relations (Kehler, 2012), and my theory captures the parallelism by showing that parasitic gaps are also subject to coherence relations (e.g. Cause-Effect, Result, Violated Expectation).

As a consequence, this theory supports the view that both parasitic and nonparasitic gaps have equal formal status (Pollard and Sag, 1994; Levine et al., 2001). Instead of assigning a special status to a parasitic gap to distinguish it from a 'true' gap (Contreras, 1981), we can simply assume that grammar allows multiple filler-gap dependencies where extraction may leave any number of gaps, and independent semantico-pragmatic conditions serve to govern the acceptability of these dependencies. This makes for a neater and simpler theory.

\section{References}

Chomsky, Noam. 1982. Some concepts and consequences of the theory of government and binding. MIT Press Contreras, Helena. 1981. A Note on Parasitic Gaps. Linguistic Inquiry 15.698-701.

Culicover, Peter. 2001. Parasitic gaps: A history. Cambridge, Mass.: MIT Press.

del Gobbo, Francesca. 2001. Appositives schmappositives in Chinese. UCI working papers in

Linguistics 7. 1-25. http://www.swtang.net/doc/study_delgobbo_rc_2001.pdf.

Engdahl, Elisabet. 1983. Parasitic gaps. Linguistics\&Philosophy 6.5-34.

Heim, Irene. 1982. The Semantics of Definite and Indefinite Noun Phrases. Doctoral Dissertation. MIT..

Hobbs, Jerry. 1979. Coherence and Coreference. Cognitive Science 1(3). 67-90.

Huybregts, Reny and van Riemsdijk, Henk. 1987. Parasitic Gaps and ATB. Proceedings of NELS 15.

Kehler, Andrew. 2012. Coherence and the coordinate structure constraint. Proceedings of BLS 22(1). http://elanguage.net/journals/bls/article/download/3162/3143.

Levine, Robert, Hukari, Thomas \& Calcagno, Michael. 2001. Parasitic Gaps in English. Current Studies in Linguistics Series 35.

Lin, Jonah. 2005. Does wh-in-situ license parasitic gaps? Linguistic Inquiry 36.298-302. http://www.mitpressjournals.org/doi/abs/10.1162/0024389053710675?journalCode=ling\#.U9D68HKSzsw

Lin, Jowang. 2003. On restrictive and non-restrictive relative clauses in Mandarin Chinese. Tsinghua Journal of Chinese Studies 33(1).199-240.

Pollard, Carl. \& Sag, Ivan. 1994. Head-driven Phrase Structure Grammar CSLI: Stanford.

Reinhart, Tanya. 1981. Pragmatics and Linguistics. An analysis of Sentence Topics. Philosophica 27.53-94.

Ting, Jen. \& Huang, Yuchi. 2008. Some Remarks on Parasitic Gaps in Chinese. Concentric 34(1).27-52.

Truswell, Robert. 2010. Events, Phrases and Questions. Oxford: Oxford University Press.

Tsai, Dylan. 1994. On economizing the theory of A'-dependencies Doctoral dissertation, MIT.

Williams, Edwin. 1990. The ATB Theory of Parasitic Gaps. The Linguistic Review 6(3). 265-279. 